\title{
GEOMETRIC PROPERTIES OF BANACH SPACE VALUED BOCHNER-LEBESGUE SPACES WITH VARIABLE EXPONENT
}

\author{
CHEN CHEng AND Jingshi Xu
}

Abstract. In this paper, the Banach space valued Bochner-Lebesgue spaces with variable exponent are introduced. Then the dual space, the reflexivity, uniformly convexity and uniformly smoothness of these new spaces are obtained. Finally the properties of the Banach valued Bochner-Sobolev spaces with variable exponent are also given. Those are a generalization of scalar valued Lebesgue and Sobolev spaces with variable exponent.

Mathematics subject classification (2010): Primary 46G10; Secondary 46A80, 46B22.

Keywords and phrases: Variable exponent, Bochner-Lebesgue space, Radon-Nikodym property, reflexivity, uniformly convexity.

\section{REFERENCES}

[1] A. AlmeidA, P. Hästö, Besov spaces with variable smoothness and integrability, J. Funct. Anal. 258 (2010), 1628-1655.

[2] A. Almeida, J. Has Anov, S. SAmKo, Maximal and potential operators in variable exponent Morrey spaces, Georgian Math. J. 15 (2008), 195-208.

[3] H. Amann, Linear and Quasilinear Parabolic Problems, Volume I: Abstract Linear Theory, Birkhäuser, Basel, 1995.

[4] L. Diening, P. HÄstÖ, S. RoudenKo, Function spaces of variable smoothness and integrablity, J. Funct. Anal. 256 (2009), 1731-1768.

[5] L. Diening, P. HARJUlehto, P. HÄSTÖ, M. RŮŽIČKA, Lebesgue and Sobolev Spaces with Variable Exponents, Lecture Notes in Mathematics 2017, Springer-Verlag, Berlin, 2011.

[6] J. Diestel, J. J. Uhl, Vector Measures, Amer. Math. Soc., 1977.

[7] P. HÄSTÖ, Local-to-global results in variable exponent spaces, Math. Res. Lett. 16 (2009), 263-278.

[8] P. Harjulehto, P. HÄstö, U. V. Le, M. Nuortio, Overview of differential equations with nonstandard growth, Nonlinear Anal. 72 (2010), 4551-4574.

[9] S. KAKUTANI, Weak convergence in uniformly convex spaces, Tohoku Math. J. 45 (1938), 188-193.

[10] H. KempKa, 2-microlocal Besov and Triebel-Lizorkin spaces of variable integrability, Rev. Mat. Complut, 22 (2009), 227-251.

[11] H. KEMPKA, Atomic, molecular and wavelet decomposition of generalized 2-microlocal Besov spaces, J. Funct. Spaces Appl. 8 (2010), 129-165.

[12] O. KovÁČIK, J. RÁKosNík, On spaces $L^{p(x)}$ and $W^{k, p(x)}$, Czech Math. J. 41 (1991), 592-618.

[13] P. C. Kunstmann, L. WeIs, Maximal-regularity for parabolic equations, Fourier multiplier theorems and $H^{\infty}$-functional calculus, Functional analytic methods for evolution equations, Lecture Notes in Math. 1855, Springer, Berlin, 65-311, 2004.

[14] R. E. Megginson, An Introduction to Banach Space Theory, Graduate Texts in Mathematics 183, Springer-Verlag, 1998.

[15] J. XU, Variable Besov and Triebel-Lizorkin spaces, Ann. Acad. Sci. Fenn. Math. 33 (2008), 511-522.

[16] J. XU, An atomic decomposition of variable Besov and Triebel-Lizorkin spaces, Armenian J. Math. 2 (2009), 1-12. 